\title{
Research on the PLE Building of Foreign Language Learners in Universities from the Perspective of Mobile Learning
}

\author{
Lili Guo \\ Heihe University \\ Heihe, China, 164300
}

\begin{abstract}
With the development of computer networking technology and multimedia technology, the research on learning environment changes from the learning content management system to the course management system and then to the virtual learning environment. Under the influence of social software, informal learning and community of practice, the research core of learning environment transfers from VLE to Personal learning environment (PLE). PLE can meet the individualized learning interests and demands, conform to the requirements of era development and deepen the development of theories on the educational technology. Guided by the theories on mobile learning, the research reflects the traditional activities of English learning, rebuilds the new mode of PLE integrating the overall correlation with dynamic balance, theoretical guidance with technical support, teaching resource sharing with service of educational achievement to guide the foreign language learning in universities of the province, looking forward to realizing a cross-situational continuous learning.
\end{abstract}

Keywords-mobile learning; foreign language learners in universities; PLE building

\section{INTRODUCTION}

The internet has changed our school life and realized the personalized learning of learners roundly. Learning software contributes to the mobile learning. On the network, learners can determine the learning objectives, choose learning contents and methods, control the learning process and evaluate as well as give the feedback, controlling autonomously.

\section{THE MEANING OF PLE}

In November 4, 2004, the academic term of "Personal Learning Environment" was first recorded on the personal learning environment seminar of Britain JISC/CETIS. It means the PLE has become another important emerging topic in the educational technology even the whole educational field. So far, the researches on the PLE have been burgeoning. Due to the appearance and application of learning software in the society, the design of learning environment has formed a new pattern--Personal Learning Environment (PLE). Under the influence of the informal learning and the individualized learning, the micro media like WeChat, weibo, micro class and micro film have gradually entered the educational field.

Fund project: 2016 Heilongjiang Province Education Science Planning Key Subject "Research on the PLE Building of Foreign Language Learners in Universities from the Perspective of Mobile Learning.
Therefore, in consideration of the mobility of learning--the mobility of students and technical support, it is important to think about how to derive mobile learning forms in the actual language teaching and provide an individualized, extensive, efficient and convenient learning environment for learners from the transmission of knowledge and knowledge construction to the situation cognition. PLE powerfully supports learners' independent study, helps learners to manage the learning like control the learning objectives, choose the learning contents, methods, processes and schedules, gather and share resources, spread and summarize opinions as well as renovate and share knowledge. In this process, the learning of learners becomes ordered.

\section{ELEMENTS TO BUILD THE PLE}

PLE brings tools and resources that can be chosen and maintained by the learners and acquired from the computer or the smart phone for learners and help them to control the learning process. Elements to build the PLE include: cooperation, tools to create the contents, content library, brief and product assortment, planning and management, evaluation and reflection. Tools in PLE refer to the learning tools under the support of information technology. The so-called learning tools refer to the media conductive to learners to search, acquire and deal with the information, communicate and cooperate, build knowledge as well as express the understanding and evaluate the learning effect through concrete methods. PLE requires learners to choose and collect the required tools, like the tools for search, integration, information processing, release and cooperation. Learners can choose tools according to their learning styles and requirements. All these help to manage the learning process. For example, an academic briefcase helps students to collect the evidence of the school work finished and more formal achievements, like finish the school work, grade and test scores. It depends on the students to open the information and share it with teachers, companions and the future employers, such as the learning experience, the language learned by them and other information. Generally speaking, it shows the learning experience of learners and personal information they want to share with others. Collaboration tools allow learners to communicate with others. The tools can be designed specially to help learners to finish a project, like wiki, or they can raise 
questions through more common tools such as social networks and Google+. Social bookmark tools can share the bookmarks of some interesting learning websites. Synchronization tools require participants to carry out real-time communication, chatting or IM and VoIP like Skype. In the management of learning, planning and monitoring tools help learners to set goals, create the to-do list and check the schedule. For example, the mind map helps learners' brainstorm and classify things requiring improvement. Periodicals help learners to record and reflect the learning process through the blog, a simple text file, or specific programs and application programs. Finally, the repository helps learners to store contents of language learning, like films (subscribe the YouTube channel), websites (subscribe the RSS abstract), and share documents, etc. Different tools are for different purposes. For example, a learner can create a Google+ page to share with other learners and keep the page for personal reflection. Most tools in PLE are not specially designed for language learning, but the frequently-used websites and application programs used by students in daily life.

\section{IMPLEMENT PLE IN THE CLASSROOM OF FOREIGN} LANGUAGE TEACHING: PROBLEMS NEED CONSIDERATION IN THE TECHNICAL LEVEL

\section{A. Do Teachers Really Need to Learn How to Use the Application Software?}

Not always. They should encourage learners to do so. You may need to know different application software, like sharing documents online, but you don't need to install or use them. In some sense, the tools in PLE are like the books in library. You don't need to read all of them but guide learners to use them. Some links connect with the websites, providing good network resources in compiling software.

\section{B. Who Build the PLE? The Answer Is the Learners}

Teachers may want to use some examples in PLE resource library to show learners what's the PLE and the tools, but students are responsible for building the PLE.

\section{Do Learners Need to Grasp More Skills to Create PLE?}

Not always. They need comfortable technology, especially the internet. But many tools used in PLE are familiar to learners, like the social networks, websites, weibo and the bbs. Most learners need to know the methods to use these tools to support their learning.

\section{THE INFLUENCE OF IMPLEMENTING PLE ON THE Teaching In The Classroom Teaching OF Foreign LANGUAGE}

\section{A. Realize the Self-Control Learning of Learners}

It is most challenging and breathtaking that the PLE can have profound influence on learning and teaching. Firstly, the PLE has changed the traditional classroom pattern. Students need to bear more responsibilities in learning. Some learners may raise some questions for the change because this is a new experience. In classroom practices, the best method for teachers is to explain the basic principles of PLE. On the other hand, teachers should assign some student-oriented learning tasks and give enough support.

\section{B. Monitor the Personal Learning}

The frequent feedback for personal learning practice is very important as well as an extra learning method. When responding to learners' reflection or records, teachers can raise the following questions: why do you decide to pay attention to this grammar? Does this activity help you to practice the knowledge points learned in class? Do you have any other ways to solve this problem? How do your classmates solve this problem?

\section{Evaluate the Implementation of PLE Learning}

The PLE doesn't aim at the learning about language but the learning concerning the organization, monitoring and critical reflection. Importantly, let learners see the time spent by you in these tasks. Just like the evaluation on learners' strategy, there is no test to manage or scores you can give. However, you can evaluate the frequency, degree when learners implement the PLE learning and the depth of learners' reflection and make some useful comments. Some teachers have successfully tried the self-evaluation of learners.

\section{Encourage the After-Class Study}

Substantially, PLE is the set to encourage students to collect student-oriented learning tools. Students need to see and use them because they support the lifelong learning. It is feasible only when learners feel the PLE directly connects with the practice of language learning and require using the required tools to finish the classroom tasks. Learners can share the research results with other learners after finishing a project and report, and other learners can evaluate it.

\section{E. Influence of PLE on Learning and Teaching Practice}

PLE can change the roles of teachers and students as well as some courses. As mentioned above, PLE provides students with more opportunities to control the learning, which may be different from the regular class exercise. Successful class teaching centers on the learners instead of teachers or the scheduled and static contents. PLE allows learners to explore things they want and need and share it with teachers. In fact, the most important advantage for teachers is that it allows teachers to understand students' situation, difficulties, preferences and backgrounds. It helps teachers to grow excellently but at the same time has higher demands for teachers' flexibility. Except for understanding and adapting to the preferences of different learners, teachers may need to play a new role in online monitoring the school work, evaluating and giving feedback for learners' posts and assignments related to the language practice finished after class. In this sense, teachers play the role of coordinator. PLE can also influence the effect of teaching evaluation. Because more attentions are paid to the lifelong learning, PLE learning does not focus on the test scores but train learners' ability in finding learning styles to improve themselves. It may need new means to replace the teaching evaluation. 


\section{CONCLUSION}

With the development of computer networking technology and multimedia technology, the research on learning environment changes form the learning content management system to the course management system and then to the virtual learning environment. Under the influence of social software, informal learning and community of practice, the research core of learning environment transfers from VLE to Personal learning environment (PLE). PLE can meet the individualized learning interests and demands, conform to the requirements of era development and deepen the development of theories on the educational technology. Under the support of PLE, learners can independently acquire the knowledge and solve the problems in learning through self-guidance, active communication and cooperation. It supports or helps the lifelong learning of learners and promotes the development of them in the long term.

\section{REFERENCES}

[1] Yu Xiaohua. Independent Study in the Personal Learning Environment [M], Nankai University Press, 2013

[2] Li Minjiao, Wang Ying. The Research Status and Development Tendency of Personal Learning Environment (PLE) in Our Country [J], Journal of Guangzhou Radio and TV University, 2013(2): 7-12

[3] Wu Yulu. Analysis on the Elements of Personal Learning Environment (PLE) [J], Journal of Jiangxi Radio and TV University, 2011(4): 46-51

[4] Wang Lifeng. Research on the Personal Learning Environment (PLE) Building from the Perspective of Knowledge Management [D], Northeast Normal University, 2014

[5] Li Dansa. Research on the Building and Application of Personal Learning Environment on the Basis of Course Learning [D], South China Normal University, 2012 